\title{
Treatment of Type II Scaphoid Nonunion Advanced Collapse Lesions by Scaphoid Distal Pole Resection and Proximal Tenodesis of Extensor Brevis Carpi Radialis: Technique Description and Case Series*
}

\section{Tratamiento de las lesiones SNAC tipo II mediante resección del polo distal escafoides y tenodesis proximal del extensor radial corto del carpo: Descripción de la técnica y serie de casos}

Niceas da Silva Gusmão Filho ${ }^{1}$ Ricardo Kaempf de Oliveira ${ }^{2}$

${ }^{1}$ Department of Hand Surgery, Hospital Geral do Estado de Alagoas, Maceió, AL, Brazil

2 Department of Hand Surgery, Santa Casa de Misericórdia de Porto

Address for correspondence Niceas da Silva Gusmão Filho, Av. Aristeu de Andrade, n492, Apto-502, Farol, Maceió, AL, 57051-090, Brazil (e-mail: niceasgfilho@gmail.com).

Alegre, Porto Alegre, RS, Brazil

Rev Iberam Cir Mano 2019;47:84-90.

\begin{abstract}
Keywords

- wrist arthritis

- carpal instability

- scaphoid nonunion

- distal scaphoid resection

- scaphoid nonunion advanced collapse (SNAC) arthritis
\end{abstract}

Objective To describe a new surgical technique and treatment outcomes of type II scaphoid nonunion advanced collapse (SNAC) lesions by scaphoid distal resection associated to the tenodesis of the remaining proximal pole with the extensor brevis carpi radialis tendon. Material and Methods This is a retrospective, observational study in which six patients were enrolled and submitted to this original technique, from February 2016 to March 2018. Only those patients with a comprehensive assessment and minimum 6 months postoperative evolution were included. Patient data, such as age, gender, and dominance, along with injury characteristics, previous therapies, complaints, and time span between appearance of the lesion and surgery were all analyzed.

Results Among the six patients assessed, four were male, with ages ranging from 28 and 46 years (mean, 38.1 years). The elapsed time between nonunion diagnosis or scaphoid fracture and definitive treatment ranged from 34 to 72 months, with an average of 48.0 months. The mean follow-up time between the surgery and final results assessment was 15.3 months, ranging from 8 to 22 months. Preoperative measured mean pain was 8.8 , ranging from 8 to 10 . At 6 months postoperatively, mean pain assessment was 1.5, ranging from 0 to 5 . We added wrist flexion and extension to assess joint range of motion. Preoperatively, the mean measure was $76.6^{\circ}$, ranging from $55^{\circ}$ to $90^{\circ}$. Postoperatively, the mean was $127.1^{\circ}$, ranging from $110^{\circ}$ to $140^{\circ}$. One patient had proximal scaphoid necrosis at

\footnotetext{
This study was performed at the Hospital Geral do Estado de Alagoas, Maceió, AL, Brazil.
}

received

May 11, 2019

accepted

July 1,2019
DOI https://doi.org/

10.1055/s-0039-1695763. ISSN 1698-8396.
Copyright $\odot 2019$ Thieme Revinter

Publicações Ltda, Rio de Janeiro, Brazil
License terms

(c) $(1) \$$ 
8 months postoperatively as a complication. The patient was treated with proximal carpectomy, with good clinical outcome; however, he did not return to his original job activities. The other five patients did return to their previous labor activities.

Conclusions Treatment of type II SNAC lesions by resection of the distal scaphoid associated to tenodesis of the remaining proximal pole with a portion of the extensor brevis carpi radialis tendon has proved to be a useful, safe technique. Having low morbidity and few complications, the treatment represents a good alternative to previously described techniques.

\section{Introduction}

The perfect carpal kinematics depends on bone and ligament integrity, that together form the carpal ring, a concept instituted by Linchman et al. ${ }^{1}$ Carpal collapse may ensue due to a solution continuity of that ring, as caused by scaphoid nonunion following neglected or inadequately treated fractures. Such lesion determines a degeneration pattern with well-defined stages known as scaphoid nonunion advanced collapse (SNAC), which initiates at the radioscaphoid joint, evolves to the scaphocapitate and lunocapitate joints, and ends at the radiolunate joint. ${ }^{2}$

In type II SNAC, the radioscaphoid joint is compromised at the most distal part of the styloid, sparing the segment in the vicinity of the scaphoid proximal pole. Several publications have demonstrated that scaphoid bone distal pole resection is a simple and practical solution for the treatment of type II SNAC lesion, thus promoting improvement of pain, range of motion, and grip strength. Nonetheless, despite of all advantages, the technique carries the risk of dorsal intercalar scaphoid instability (DISI) pattern as an undue result. ${ }^{3-5}$

We propose a new treatment technique for type II SNAC lesions by resection of the distal scaphoid associated to tenodesis of the remaining proximal pole with a portion of the extensor brevis carpi radialis (EBCR) tendon (-Figs. 1A and 1B). The technique yields the maintenance of lunocapitate angles within physiological range $\left(<15^{\circ}\right)$, thus avoiding DISI type instability.

\section{Methods}

This is a retrospective, observational study. After obtaining approval of the institutional ethics committee, type II SNAC patients were submitted to distal scaphoid resection (DSR), associated to a tenodesis to the proximal EBCR tendon. The study length was from February 2016 to March 2018. Six patients were enrolled. Only patients with a comprehensive assessment, and a minimum of 6 months postoperative follow-up were included.

Surgical indication criteria and chosen technique included pain and functional impairment lasting longer than 6 months, along with no improvement with conservative measures (such as physical therapy and orthoses). Our retrospective review assessed clinical and radiographic results, along with possible complications due to the surgery.

Patients with previous surgeries, infections, or those with less than 6 months follow-up were not included in the study. We have not indicated this technique for SNAC patients caused by a proximal scaphoid fracture.

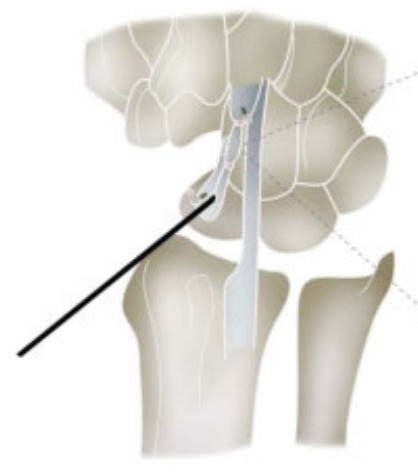

A

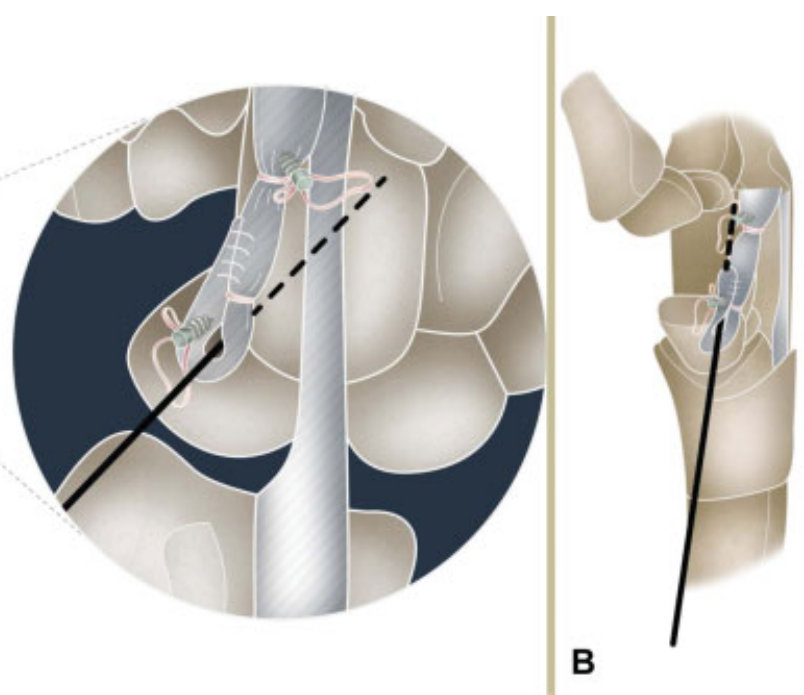

Fig. 1 Proposed technique for the treatment of type II scaphoid nonunion advanced collapse lesions by the resection of the distal scaphoid associated to a tenodesis of a portion from the extensor brevis carpi radialis to the remaining proximal pole, together with bone anchor fixation onto the dorsum of the capitate and the proximal scaphoid bones. The figure shows the wrist on dorsal (A) and lateral (B) views. 
Patient data such as age, gender, occupation, and dominance, along with injury characteristics, previous therapies, complaints, and time span between the lesion appearance and surgery were all analyzed. Patient degree of satisfaction was also taken into consideration. Pain was assessed both preoperatively and at the final assessment through visual analogue scale (VAS) (from 0 to 10 , in which 0 means absence of pain, and 10 means the worst pain one can feel). Regarding the procedure, surgery duration and postoperative immobilization time were recorded. A subjective assessment and wrist range of motion and grip, as compared with the contralateral side, besides possible complications, such as infection, hypertrophic scarring, rigidity, instability, or degeneration, were all taken into consideration at the final analysis of the results. The time to return to work (or to normal activities, in the case of a retired patient) was recorded (Mayo Clinic Score). ${ }^{6}$

After the procedure, patients were seen at weekly intervals during the $1^{\text {st }}$ month, and at every 30 days until 6 months of follow-up; by then, the final assessment was performed. All patients were personally examined by one of the authors (-Table 1).

\section{Surgical Technique}

Patient lies in supine position, with brachial plexus block, and a tourniquet is applied. A longitudinal, italic " $\mathrm{S}$ " incision is placed between the central and radial thirds at the dorsum of the wrist. Radial nerve sensitive branches are radially retracted. An opening of the extensor retinaculum is performed with the elevation of a $1-\mathrm{cm}$ wide flap that is detached from the radial portion of the first extensor compartment, keeping the insertion at the ulnar border of the $4^{\text {th }}$ compartment. This facilitates retracting of the extensor tendons, thus exposing the joint capsule that is longitudinally incised at the central portion for the elevation of two flaps: one radially, and the other ulnarly.

Next, the distal radial styloid resection and neurectomy of posterior interosseous nerve capsular branches are routinely performed. Then, the scaphoid distal resection is performed through the nonunion plane (-Figs. 2A and 2B).

The bleeding surface of the proximal pole is smoothed, and a $1.5-\mathrm{mm} \mathrm{K}$-wire is introduced on the back of the lunate bone to be used as a joystick to assist the alignment correction of the first carpal row. Next, a stripe of the EBCR tendon with a third of its thickness is elevated, keeping the distal insertion at the base of the third metacarpal bone. There should be enough length so that the tendon can be inserted on the proximal scaphoid bone fragment, along with a $2-\mathrm{cm}$ long excess for a loop, and to be re-sutured back.

At this time, a temporary fixation of the proximal scaphoid to the capitate is performed with a second $1.5-\mathrm{mm}$ K-wire, keeping the lunate bone at $15^{\circ}$ of flexion ( - Fig. 2C). The exposure of the proximal scaphoid is facilitated by a previous radius styloidectomy. The K-wire may also be passed from the triquetrum to the capitate when the proximal scaphoid fragment is small. After carpal stabilization, the lunate dorsal Kwire may be removed.

The EBCR tendon stripe is initially fixated to the capitate body and then to the scaphoid with $2.5 \mathrm{~mm}$ anchors. The double-anchorage mount aims to avoid a possible bowstring formation on the back of the wrist (-Figs. 3A and 3B). The tenodesis should be firmly tensioned, which can be achieved by suturing the tendon to itself, after the fixation on the scaphoid. The K-wire introduced in the scaphoid is also employed to assist on tenodesis stabilization and tension ( - Fig. 3C). A

Table 1 Patient demographics and data before and After the scaphoid distal pole resection associated to extensor brevis carpi radialis tenodesis

\begin{tabular}{|c|c|c|c|c|c|c|c|c|c|c|c|c|c|}
\hline \multirow[t]{2}{*}{ Patient } & \multirow[t]{2}{*}{$\begin{array}{l}\text { Age } \\
\text { (years) }\end{array}$} & \multirow[t]{2}{*}{ Gender } & \multirow[t]{2}{*}{ Side } & \multicolumn{2}{|l|}{ Nonunion } & \multicolumn{2}{|c|}{$\begin{array}{l}\text { Pain scale } \\
\text { (VAS) }\end{array}$} & \multicolumn{2}{|c|}{$\begin{array}{l}\text { Flexion- } \\
\text { extension } \\
\text { mobility }\end{array}$} & \multicolumn{2}{|c|}{ Grip strength } & \multirow[t]{2}{*}{$\begin{array}{l}\text { Postop } \\
\text { follow-up } \\
\text { (months) }\end{array}$} & \multirow[t]{2}{*}{ Complications } \\
\hline & & & & $\begin{array}{l}\text { Evolution } \\
\text { time } \\
\text { (months) }\end{array}$ & Type & Preop & Postop & Preop & Postop & $\begin{array}{l}\text { Preop } \\
\text { (kgf) }\end{array}$ & $\begin{array}{l}\text { Postop } \\
\text { (kgf) }\end{array}$ & & \\
\hline 1 & 28 & $M$ & $R$ & 36 & $\begin{array}{l}\text { Stable } \\
\text { Mid-third } \\
\text { Transverse }\end{array}$ & 8 & 0 & $90^{\circ}$ & $140^{\circ}$ & 22 & 36 & 17 & None \\
\hline 2 & 30 & $\mathrm{~F}$ & $\mathrm{R}$ & 48 & $\begin{array}{l}\text { Stable } \\
\text { Mid-third } \\
\text { transverse }\end{array}$ & 8 & 0 & $80^{\circ}$ & $135^{\circ}$ & 22 & 30 & 22 & None \\
\hline 3 & 46 & $M$ & $\mathrm{R}$ & 72 & $\begin{array}{l}\text { Stable } \\
\text { mid-third } \\
\text { transverse }\end{array}$ & 10 & 2 & $85^{\circ}$ & $124^{\circ}$ & 17 & 28 & 5 & None \\
\hline 4 & 45 & $\mathrm{~F}$ & $R$ & 44 & $\begin{array}{l}\text { Unstable } \\
\text { mid-third } \\
\text { oblique }\end{array}$ & 9 & 1 & $70^{\circ}$ & $127^{\circ}$ & 22 & 29 & 16 & None \\
\hline 5 & 36 & M & $\mathrm{R}$ & 34 & $\begin{array}{l}\text { Unstable } \\
\text { mid-third } \\
\text { oblique }\end{array}$ & 9 & 5 & $55^{\circ}$ & $100^{\circ}$ & 18 & 28 & 12 & $\begin{array}{l}\text { Proximal } \\
\text { scaphoid } \\
\text { necrosis }\end{array}$ \\
\hline 6 & 44 & $M$ & $R$ & 54 & $\begin{array}{l}\text { Stable } \\
\text { mid-third } \\
\text { transverse }\end{array}$ & 9 & 1 & $80^{\circ}$ & $137^{\circ}$ & 20 & 31 & 17 & None \\
\hline
\end{tabular}

Abbreviations: M, male; F, female; R, right; VAS, visual analogue scale; Preop, preoperative; Postop, postoperative. 


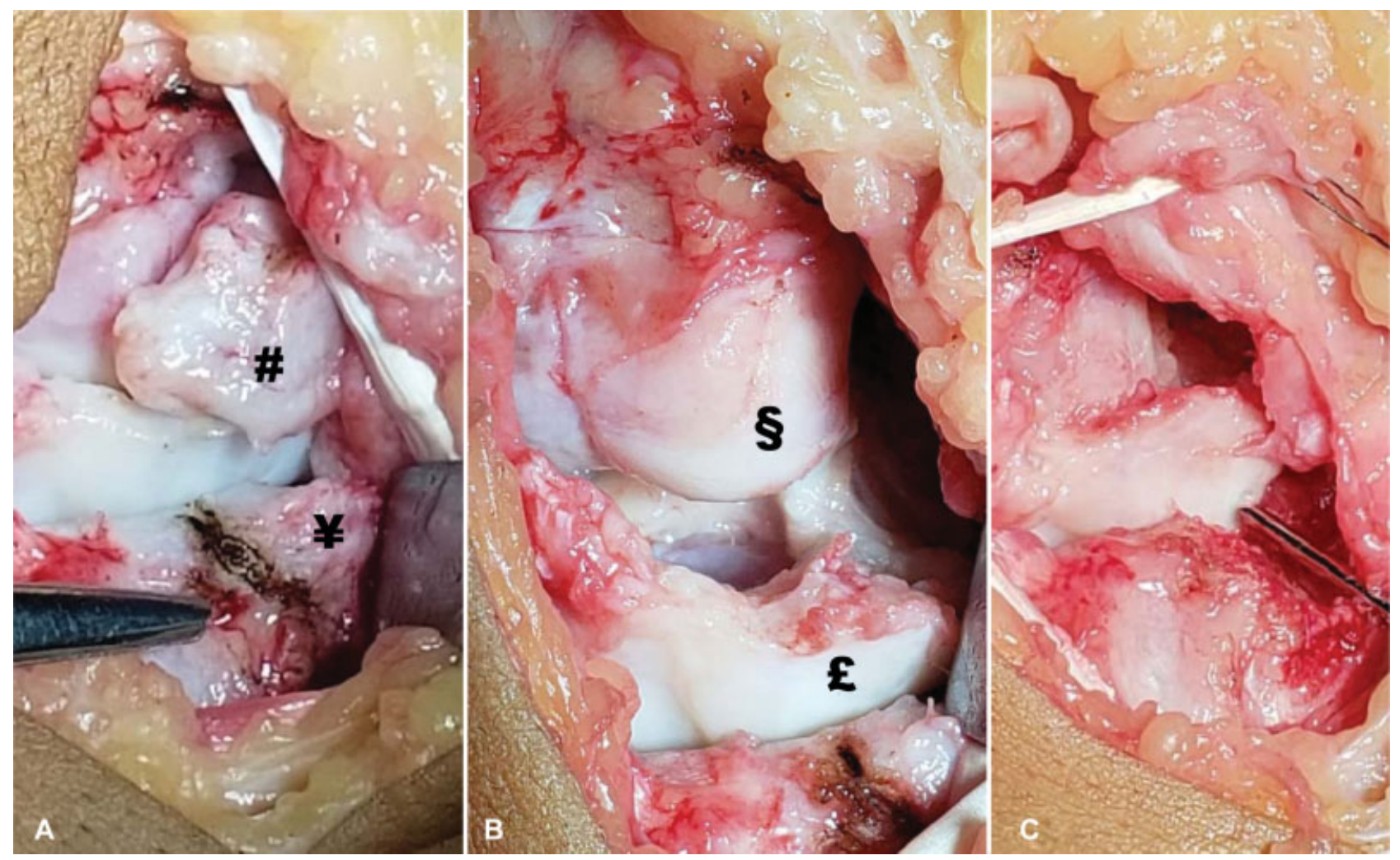

Fig. 2 The radius styloid process (\#) and the distal pole of the scaphoid bone ( $¥)$ are seen through a longitudinal, italic "S" incision on the back of the wrist (A). After distal scaphoid and distal radius styloid resection, the capitate $(\S)$ and the proximal scaphoid $(£)$ are visualized (B). Fixation of the proximal scaphoid to the capitate with a 1.5 -mm K-wire, keeping the lunate bone at $15^{\circ}$ of flexion (C).

proximal, dorsal scaphoid scarification is performed to improve the bone fixation of the transferred tendon by forming a groove near the anchor site. Fluoroscopy is employed to assess the correct placement of bone anchors and K-wires, along with the lunate and capitate bones alignment.

The capsule and extensor retinaculum are sutured by planes ( - Fig. 3D). The wrist is immobilized with a short forearm cast for 8 weeks; by that time, the K-wire is removed. Patients are followed-up on a weekly basis for a month and are usually submitted to a rehabilitation protocol with a hand therapist. They are also oriented to perform lengthening and range-of-motion exercises at home.

\section{Results}

Of the 6 patients assessed, 4 were male and 2 were female, with ages ranging from 28 to 46 years (mean, 38.1 years). All compromised limbs were the dominant ones. The elapsed time between nonunion diagnosis or scaphoid bone fracture and definitive treatment ranged from 34 to 72 months, with an average of 48.0 months. Mean follow-up time between the surgery and final results assessment was 15.3 months, ranging from 8 to 22 months.

All patients proved to have stage II SNAC by computerized tomographic assessment, showing compromise of the joint between the radius and the scaphoid, but with no proximal capitate lesion. All six patients of our series had mid-third scaphoid bone nonunion; in four patients, the nonunion line was transverse, and, in two patients, the nonunion line was oblique.

Pain assessment was performed by means of a VAS on a ruler. Preoperatively, mean pain was 8.8 , ranging from 8 to 10. At the 6-months postoperative follow-up, mean pain was 1.5 , ranging from 0 to 5 .

We added wrist flexion and extension to measure joint range of motion. Preoperatively, the mean measure was $76.6^{\circ}$, ranging from $55^{\circ}$ to $90^{\circ}$. Postoperatively, the mean was $127.1^{\circ}$, ranging from $110^{\circ}$ to $140^{\circ}$.

Grip strength was assessed with a Jamar dynamometer on position \#3, with the elbow flexed at $90^{\circ}$, and the nonsupported upper limb over the table. Preoperatively, patients had mean strength of $20.1 \mathrm{kgf}$, ranging from 17 to 22 . Postoperative mean strength was $30.3 \mathrm{kgf}$, ranging from 28 to 36 .

Preoperative lateral wrist radiographs showed an increased angle between the lunate and capitate bones, a DISI-type dissociation pattern with an average of $25^{\circ}$, ranging from 19 to $32^{\circ}$. Regarding the radiologic pattern, the measurement of lunocapitate angle remained $<15^{\circ}$ in all patients, and a DISI-type instability evolution was not observed. (-Fig. 4).

One patient presented proximal scaphoid necrosis as a complication at 8 months postoperatively. The patient was treated with proximal row carpectomy with a good clinical outcome; however, he did not return to his original job activities. There were no other serious complications such 

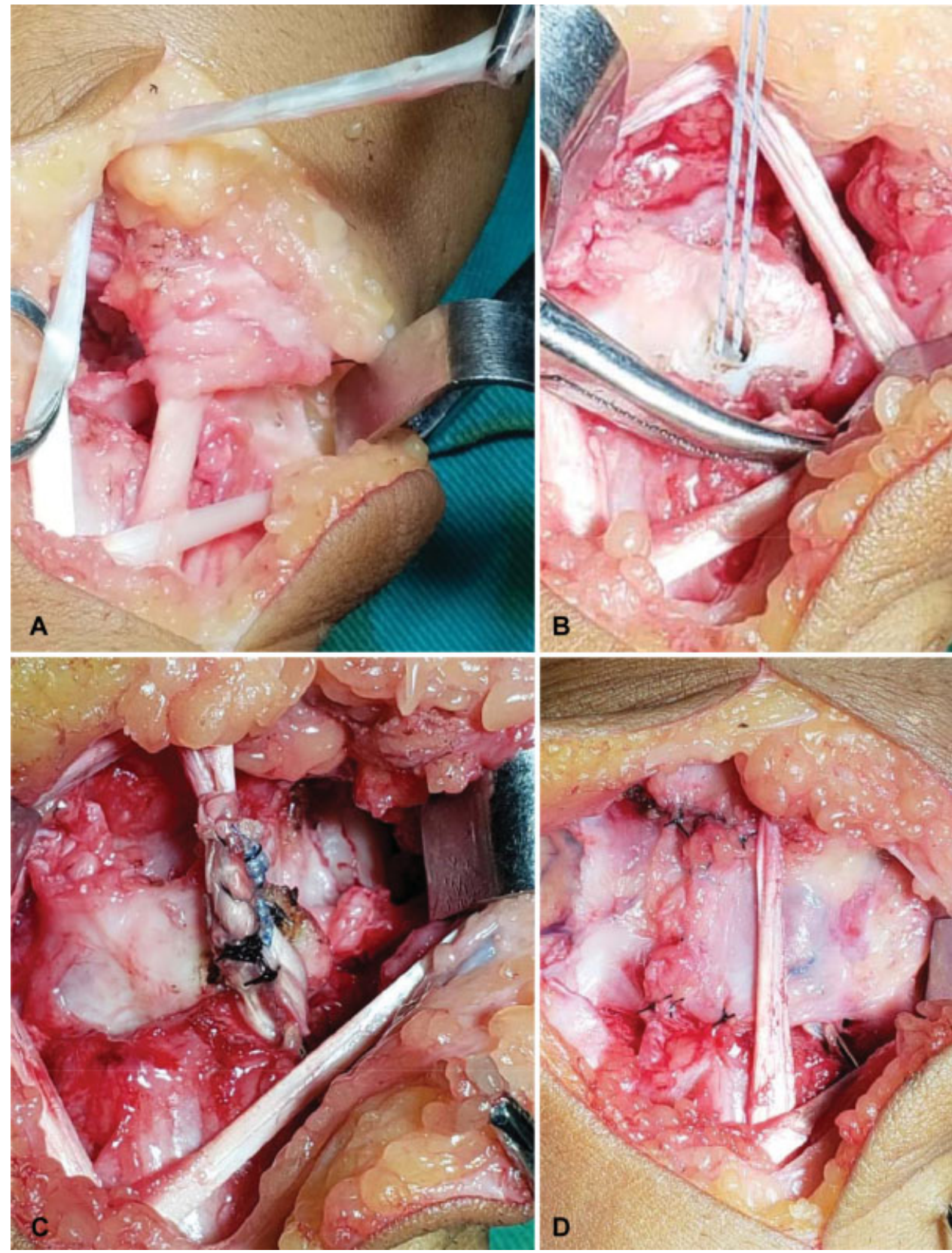

Fig. 3 Elevation of extensor brevis carpi radialis tendon trip with one third of its thickness (A). Extensor brevis carpi radialis tendon fixation onto the scaphoid with $2.5 \mathrm{~mm}$ bone anchor (B). Tenodesis fixation with sufficient tension and suture onto itself after scaphoid fixation (C). Suture of the wrist joint capsule (D).

as infection, hypertrophic scarring, or complex regional pain syndrome. The other five patients did return to their previous labor activities.

There was a significant improvement in 5 patients, who have risen from $42 \pm 14$ points to $91 \pm 5$ points on the clinical evolution as measured by the Mayo Clinic Score. One patient had little improvement, from 53 to 64 points; he evolved later to a necrosis of the proximal pole.

We asked patients to rank their improvement as very satisfied; satisfied; little satisfied; and unsatisfied regarding treatment outcomes. Of a total of six patients, four reported to be very satisfied; one patient was satisfied; and the other little satisfied.

\section{Discussion}

The treatment of carpal collapse due to scaphoid nonunion has been well-stablished in the literature, with definite treatment options for each stage. Regarding specifically to stage II, it has been cited: simple DSR; ${ }^{3-6}$ total scaphoid resection associated to the tenodesis of the flexor carpi radialis; $^{7}$ total scaphoid resection associated to carpal mini-arthrodesis; total scaphoid resection associated to capsulodesis $^{8}$ and the carpectomy of the first-row carpal bones. $^{9}$

All those procedures aim to relieve pain, improve the range of motion, and increase strength. Simple DSR is a 

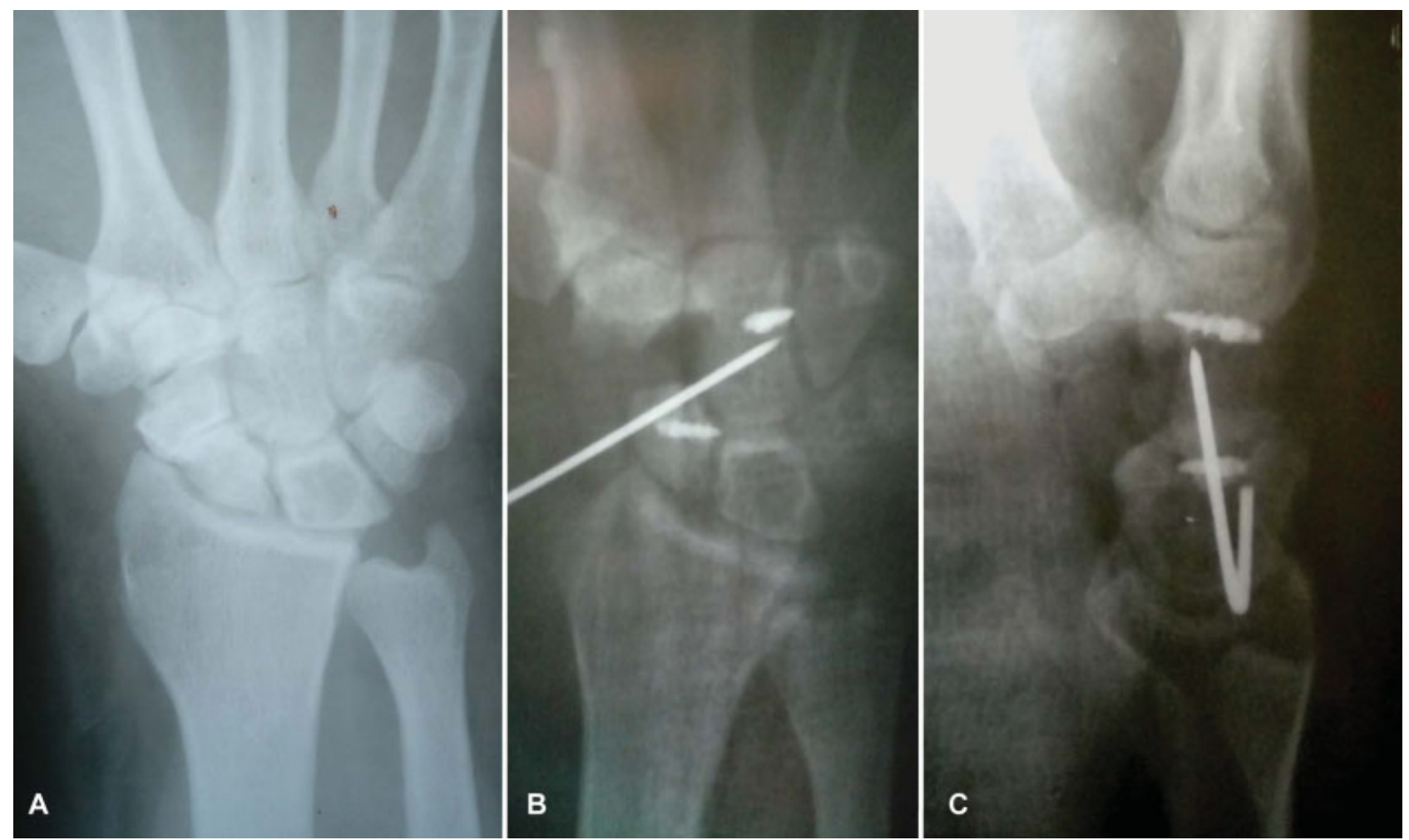

Fig. 4 Preoperative anteroposterior views showing scaphoid nonunion and type Il scaphoid nonunion advanced collapse lesion (A). Radiographs showing the technique comprising resection of the distal scaphoid associated to the tenodesis of a portion from the extensor brevis carpi radialis onto the remaining proximal pole, along with bone anchor fixation onto the dorsum of the capitate and the proximal scaphoid. Correction of dorsal intercalar scaphoid instability (DISI) pattern as an undue result deformity, as revealed in the lateral view (C).

practical, easily reproducible technique, and its results testify that the procedure does improve range of motion, relieves the pain, and increases grip strength. Nonetheless, it has been observed that there is an evolution toward a DISI-type instability pattern, leading to an increased lunocapitate angle, a fact that worsen patients' clinical evolution. ${ }^{5}$ Besides, Karmal et al cited that the DISI pattern associated to midcarpal dissociation that may occur after scaphoid distal fragment excision is aggravated by the dorsal carpal ligament injury, which would work as a container between the triscaphoid and the triquetral-hamate joints, thus leading to a painful midcarpal instability. ${ }^{10}$

Luchetti et $\mathrm{al}^{7}$ created a technique that associates the transfer of the flexor carpi radialis segment that is sutured over itself after looping the radio-triquetral ligament to avoid carpal ulnar translation, and a DISI pattern after total resection of the scaphoid. They have had employed the technique in 18 patients, and described procedure failure in 4 cases; another 4 patients were lost to follow-up; and the 10 remaining patients presented satisfactory clinical results on the Mayo Wrist Score, which had a gain of 23 points-from 52 to 75 points. However, they had emphasized that the radiologic pattern was rather precarious, as characterized by increased DISI deformity, lunate and triquetrum ulnar translation, and, in some cases, a contact between the capitate and the lunate facet, bearing an evident chondral damage. Comparing that technique to the one proposed by the authors of this article, we have noted that there was neither a disharmonic pattern nor a proximal migration of the capitate bone in any of our patients, thus maintaining carpal height along with equitable radial distribution of axial forces from the capitate head and lunate and the remaining pole of the scaphoid bone.

The dorsal and volar wrist capsule suture procedure at the immediately radial portion to the lunocapitate joint, after complete scaphoid excision, has been described to keep the capitate bone aligned to the lunate bone, so that the need of an arthrodesis is avoided. Good functional results have been described with that technique; ${ }^{8}$ nonetheless, besides being more technically demanding to be performed, the procedure creates an overload onto the lunate bone due to the absence of the scaphoid by keeping the radial facet of the capitate head uncovered. Our technique has the advantage of preserving carpal architecture by avoiding capitate head radial translation by keeping this structure in a bony framework formed by the lunate and the proximal portion of the scaphoid bones.

The proximal carpectomy has the advantage of keeping a good range of motion, despite grip strength limitation. That procedure has a restrict indication for cases where there is no chondral lesion, either of the proximal capitate, or of the radius lunate fossa. In a retrospective study with a follow-up of more than 15 years, there was evidence that the procedure alleviates the pain, but it does not eliminate the pain. As time goes by, there is also a gradual reduction of the range of motion achieved initially, a fact that had direct correlation to the degeneration degree of the radiocapitate joint. ${ }^{9}$ Biomechanical 
studies have suggested that the progression of the degenerative process of that joint is due to the morphologic incongruity between the surfaces of the capitate and radius lunate fossa, which generates increased pressure onto a small contact area. ${ }^{9}$ Ali et al suggested that in young, high-demand patients other treatment alternatives should be considered, but not carpectomy. $^{9}$

The total resection of the scaphoid bone associated to some kind of partial carpal arthrodesis (four-corner arthrodesis or radiolunate arthrodesis) is in general indicated for the treatment of type III SNAC, which is normally associated to a capitate head chondral lesion.

Comparative data from the literature show discrepant results among main wrist-preserving techniques. ${ }^{3}$ Regarding increased grip strength that is postoperatively achieved, when compared with the contralateral side, there is an equivalence: $75 \%$ for DSR; $70 \%$ for total scaphoid resection associated to partial carpal arthrodesis; and $78 \%$ in cases of proximal carpectomy.

Nonetheless, regarding mean increased range of motion for flexion-extension, we found $43^{\circ}$ for DSR; $21^{\circ}$ for total scaphoid resection associated to partial carpal arthrodesis; $24^{\circ}$ in cases of proximal carpectomy; ${ }^{3}$ and $10^{\circ}$ in cases of total scaphoid resection associated to capsule suturing. ${ }^{8}$ The following results were reported regarding radioulnar deviation: $41^{\circ}$ for DSR; $15^{\circ}$ for total scaphoid resection associated to partial carpal arthrodesis; $24^{\circ}$ for proximal carpectomy; ${ }^{3}$ and the loss of $2^{\circ}$ from total scaphoid resection associated to capsule suturing. ${ }^{8}$ These data demonstrate the superiority of our results when compared with techniques that advocate partial carpal fusions associated to total scaphoid excision, or to scaphoid resection and capsule suturing.

There was no evidence of arthrosis from the lunocapitate or scaphocapitate joints in our series, which overlaps with the literature findings.

A severe complication ensued in patient 5 , scaphoid necrosis. The lesion was diagnosed on the late postoperative period ( 8 months) and was treated by proximal carpectomy, with good clinical results. There could have been signs of vascular compromise at the nonunion when exams prior to the first surgical procedure were assessed, although with there no evidence has been found. Maybe that patient did not present conditions to undergo the proposed technique. We had no cases of either pin-tract or soft-tissue infection, or any case of reflex sympathetic dystrophy.

Criticisms to the procedure are bound to technical restrictions, such as the conjoint insertion of a bone anchor and K-wire onto the scaphoid proximal fragment. This fact may have influenced on the proximal scaphoid necrosis of patient 5 . Hence, we stress that K-wire insertion to fix the scaphoid to the capitate shall be performed in one attempt, if possible.

The DSR associated to tenodesis with a segment of the EBCR renders the alignment between both carpal rows, thus reconstructing the carpal kinematics. That avoids DISI instability, which is the main complication of other techniques.
Future comparative studies need to be conducted in order to clarify whether there is a real advantage in increasing the complexity of the technique toward the neutralization of the first carpal row positioning, along with its influence on the final results, as compared with the classical techniques.

\section{Conclusion}

Despite the small series of cases, we understand that distal scaphoid resection associated to EBCR segment tenodesis has demonstrated to be a useful method for the treatment of type II SNAC. The technique preserves carpal height and grip strength besides keeping the stability between the proximal portion of the capitate and the lunate joint surface, together with the proximal scaphoid. The method is restricted for cases in which there are no chondral changes of the capitate head, having the additional benefit of a possible reversion to any other technique if the need arises in the future (such as carpectomy, partial carpal arthrodesis, or a total wrist arthrodesis). Having in mind that cost and learning curve must be taken into account, our conclusion is that the technique is an effective alternative to those classic procedures employed for the treatment of type II SNAC lesions.

\section{Conflict of Interest}

The authors declare that they have no conflicts of interest.

\section{References}

1 Lichtman DM, Bruckner JD, Culp RW, Alexander CE. Palmar midcarpal instability: results of surgical reconstruction. J Hand Surg Am 1993;18(02):307-315

2 Watson HK, Ballet FL. The SLAC wrist: scapholunate advanced collapse pattern of degenerative arthritis. J Hand Surg Am 1984;9 (03):358-365

3 Malerich MM, Clifford J, Eaton B, Eaton R, Littler JW. Distal scaphoid resection arthroplasty for the treatment of degenerative arthritis secondary to scaphoid nonunion. J Hand Surg Am 1999; 24(06):1196-1205. Doi: 10.1053/jhsu.1999.1196

4 Soejima O, Iida H, Hanamura T, Naito M. Resection of the distal pole of the scaphoid for scaphoid nonunion with radioscaphoid and intercarpal arthritis. J Hand Surg Am 2003;28(04):591-596. Doi: 10.1016/S0363.5023(03)00181-3

5 Ruch DS, Papadonikolakis A. Resection of the scaphoid distal pole for symptomatic scaphoid nonunion after failed previous surgical treatment. J Hand Surg Am 2006;31(04):588-593

6 Amadio PC, Berquist TH, Smith DK, Ilstrup DM, Cooney WP III, Linscheid RL. Scaphoid malunion. J Hand Surg Am 1989;14(04):679-687

7 Luchetti R, Garcia-Elias M, Heras-Palau C, Atzei A. Scaphoidectomy and midcarpal tenodesis for SNAC 2. In: Herzberg G (Ed.) Scaphoïde Carpien 2010. Fractures et pseudoarthroses. Sauramps MedicalMontpellier2010:387-393

8 Trumble TE, Rafijah G, Alexander H, Waitayawinyu T. Scaphoidectomy and Capsulodesis for SNAC or SLAC Stage II. J Wrist Surg 2012;1(02):129-134. Doi: 10.1055/s-0032-1329615

9 Ali MH, Rizzo M, Shin AY, Moran SL. Long-term outcomes of proximal row carpectomy: a minimum of 15-year follow-up. Hand (N Y) 2012;7(01):72-78

10 Kamal RN, Chehata A, Rainbow MJ, Llusá M, Garcia-Elias M. The effect of the dorsal intercarpal ligament on lunate extension after distal scaphoid excision. J Hand Surg Am 2012;37(11):2240-2245. Doi: 10.1016/j.jhsa.2012.07.029 